needles, m. p. $180-181^{\circ}, \operatorname{mix} \theta$ m. p. with dibromo-d-sesamin $181-183^{\circ}$.

The author wishes to express his gratitude to Statens Tekniska Forskningsräd for financial support.

1. Carnmalm, B., Erdtman, H. and Pelcho. wicz, Z. Acta Chem. Scand. 9 (1955) 1111 ; Carnmalm, B. and Erdtman, H. Chemistry \& Industry 1955570.

2. Erdtman, H. in Paech, K. and Tracey, M. V. Moderne Methoden der Pflanzenanalyse, Springer, Heidelberg, Vol. III, p. 441.

3. Peinemann, K. Arch. Pharm. 234 (1896) 204 , p. 245.

4. Halberkann, J. Ibid. 254 (1916) 246.

Received December 3, 1955.

\section{X-Ray Crystallographic Data on some Nucleic Acid Components}

\author{
8. FURBERG and A. HORDVIK
}
Institute of Chemistry, University of Bergen, Bergen, Norway and

K. T A U G B ø L

\section{Joint Establishment for Nuclear Energy Research, Lillestrøm, Norway}

- Ray crystal structure analysis of de-
may be expected to give valuable informa-
tion on the structure of the macromolecule.
The four nucleosides from RNA have
earlier been studied by one of us ${ }^{1}$. In this
paper the results of a preliminary investi-
gation of some other nucleic acid compo-
nents are reported.

Weissenberg and oscillation photographs were taken, using $\mathrm{Cu} K \alpha$ and $\mathrm{F} \theta K \alpha$ radiation. Unit cell dimensions and space groups were derived and densities measured by the flotation method. The values given are believed to be accurate to within i $\%$.

Crystals of thymine, D-ribose, 2-deoxyD-ribose, deoxycytidine hydrochloride and thymidine were examined with the following result:

Thymine. Crystals grown from alcohol are needleshaped, elongated along $b$, with
$\{100\}$ prominent, whereas from water parallelepipeds are obtained, with all faces about equally developed. Both types of crystals are monoclinic with cell dimensions $a=$ $12.87 \AA, b=6.83 \AA, c=6.72 \AA$ and $\beta=105^{\circ}$. The density was found to be $1.46 \mathrm{~g} / \mathrm{cm}^{3}$ and there are four (calculated 3.97) molecules in the unit cell. The only systematic absences occur in the $h 0 l$ reflections for $l$ odd and in the $0 k 0$ reflections for $k$ odd. The space group is therefore $P 2_{1} / c$.

D-Ribose. Recrystallisation from a number of solvents yielded extremely small crystals, or syrups. From the melt, however, crystals big enough for X-ray work were grown at about $60^{\circ} \mathrm{C}$. They had the shape of needles and were elongated along c. The diagrams showed them to be monoclinic twins with (100) as twin-plane. The twinning was difficult to detect, as the cell dimensions happen to be such that the reflections from the two twinned crystals very nearly coincide. The cell dimensions are: $a=6.57 \AA, b=21.59 \AA, c=4.80 \AA$ and $\beta=113^{\circ}$. The density was found to be $1.59 \mathrm{~g} / \mathrm{cm}^{3}$, corresponding to four molecules in the unit cell. The calculated density is also $1.59 \mathrm{~g} / \mathrm{cm}^{3}$. The space group is $P 2_{1}$.

Although a great number of simple sugars have been investigated by $X$-ray crystallographic methods by Cox et al. ${ }^{2}$, and others, we have found no crystal data on ribose or 2-deoxy-ribose in the literature.

2-Deoxy-D-ribose. From the melt very thin flakes were obtained, with $\{100\}$ prominent. The X-ray diagrams were rather poor; however, they showed that the crystals probably are orthorhombic, with $a=11.36 \AA, b=10.65 \AA$ and $c=4.91 \AA$. The absences indicate the space group $P 2_{1} 2_{1} 2_{1}$. Four molecules $\mathrm{C}_{5} \mathrm{H}_{10} \mathrm{O}_{4}$ per unit cell gives a calculated density of $1.50 \mathrm{~g} / \mathrm{cm}^{3}$.

Thymidine. This nucleoside crystallises in well-developed orthorhombic prisms elongated along $c$, with $a=16.27 \AA$, $b=13.86 \AA$ and $c=4.86 \AA$. Four molecules per unit cell corresponds to a density of $1.47 \mathrm{~g} / \mathrm{cm}^{3}$. Reflections $h 00$ and $0 k 0$ are absent for odd values of $h$ and $k$ respectively. The $00 l$ reflections were not all recorded, but as 001 and 003 appear to be absent, the space group is probably $P 2_{1} 2_{1} 2_{1}$.

Deoxycytidine hydrochloride. Thin, monoclinic needles elongated along $c$, with $a=7.03 \AA, b=17.70 \AA, c=5.15 \AA$ and $\beta=117^{\circ}$. Space group $P 2_{1}$. Two mole- 
cules in the unit cell gives a calculated density of $1.52 \mathrm{~g} / \mathrm{cm}^{3}$.

We wish to thank Dr. S. G. Loland, Institutt for Ernæringsforsking, Universitetet i Oslo, for a semple of 2-deoxy-D-ribose and Dr. P. Reichard, Karolinska Institutet, Stockholm, for samples of thymidine and deoxycytidine hydrochloride.

1. Furberg, S. Acta Chem. Scand. 4 (1950) 751.

2. Cox, E. G., Goodwin, T. H. and Wagstaff, A. I. J. Chem. Soc. 1935 978, 1495.

Received December 2, 1955.

\section{Space Groups and Molecular Symmetries of Two Thiocyanates OLAV FOS8}

Institutt for uorganisk kjemi, Norges tekniske høgskole, Trondheim, Norway

$\mathbf{T}$ he unit cells and spece groups of two simple, covalent thiocyanates have been determined from single-crystal oscillation and Weissenberg photographs, using copper radiation, $\lambda(\mathrm{CuKa})=1.542 \AA$.

Sulphur dithiocyanate ${ }^{1}, \mathrm{~S}(\mathrm{SCN})_{2}$. Orthorhombic bipyramidal, $a=10.12 \AA, b=$ $12.83 \AA, c=4.34 \AA$. Four molecules per unit cell; density, calc. 1.75 , found 1.76 $\mathrm{g} / \mathrm{cm}^{3}$. Systematic absences, $0 \mathrm{kl}$ when $k+l$ is odd, $h k 0$ when $h$ is odd. The unit cell dimensions, the absences, and the relative intensities of the reflections show that the crystals are isomorphous with those of selenium dithiocyanate ${ }^{2}, \mathrm{Se}(\mathrm{SCN})_{2}$, and selenium diselenocyanate ${ }^{*}, \mathrm{Se}(\mathrm{SeCN})_{2}$. The space group is thus $D_{2 h}{ }^{16}-$ Pnma. From the known structures of the selenium ana. logues ${ }^{2,3}$ it follows that the sulphur dithiocyanate molecule has an unbranched chain structure, with the middle sulphur atom located in a crystallographic mirror plane.

The compound was prepared from sulphur dichloride by reaction with an excess of silver thiocyanate suspended in carbon disulphide, and was recrystallized from the same solvent. Silver thiocyanate was found to react better than mercuric thiocyanate 4 The crystals occur as plates $\{010\}$, bounded by $\{110\}$ and $\{111\}$, and usually very thin. The bulk of crystals became yellow in the course of a day, due to the formation of an insoluble polymer 1, 4, but individual crystals could be picked which were sufficiently stable.

Ethylene thiocyanate, $\left(\mathrm{CH}_{2} \mathrm{SCN}\right)_{2}$. Orthorhombic bipyramidal, $a=7.39 \AA$, $b=7.81 \AA, c=11.48 \AA$. Four molecules per unit cell; density, calc. 1.45, found $1.42 \mathrm{~g} / \mathrm{cm}^{3}$. Systematic absences, $0 k l$ when $k$ is odd, $h 0 l$ when $l$ is odd, $h k 0$ when $h$ is odd. The spece group is thus $D_{2 h}{ }^{15}-P b c a$, which has eightfold general positions, and two fourfold sets of symmetry centres as special positions. With four molecules per unit cell, it follows that the ethylene thiocyanate molecules are centrosymmetric in the crystels. This agrees with the finding from infrared messurements ${ }^{5}$ that the compound exists in trans configuration in the solid state.

Recrystallized from chloroform, the compound was obtained as plates $\{010\}$, or as perfect bipyramids $\{111\}$ with, also here, $\{010\}$ developed.

Further work on the crystal structures of the two thiocyanates is intended.

1. Lecher, H. and Wittwer, M. Ber. 55 (1922) 1481.

2. Ohlberg, S. M. and Vaughan, P. A. J. Am. Chem. Soc. 76 (1954) 2649.

3. Aksnes, O. and Foss, O. Acta Chem. Scand. 8 (1954) 1787.

4. Baroni, A. Atti R. Accad. Lincei [6] 23 (1936) 139.

5. Quagliano, J. V. and Mizushima, S.-I. J. Am. Chem. Soc. 75 (1953) 6084.

Received November 30, 1955.

\section{"Trans" Naphthodioxan Charac- terized by its Mercuric Chloride Compound}

0. HASSEL and CHR. RØMMING

Universitetets Kjemiske Institutt, Blindern-Oslo, Norway

In 1950 Furberg and Hassel 1 determined the crystal structure of the lower melting compound (m. p. $111^{\circ} \mathrm{C}$ ) found in the reaction between 2,3-dichloro-1,4-dioxan and ethylene glycol. They found

Acta Chem. Scand. 10 (1956) No. 1 